\title{
Broad-scale spatial factors outweigh the influence of habitat structure on the fauna associated with a bioengineer
}

\author{
Victoria J. Cole*, Christopher D. McQuaid \\ Coastal Research Group, Department of Zoology and Entomology, Rhodes University, PO Box 94, Grahamstown 6140, \\ South Africa
}

\begin{abstract}
Mechanisms operating at regional scales, such as nutrient supply or temperature, are often modified within biogenic habitats via changes in habitat structure created by the bioengineer. By examining beds of the brown mussel Perna perna and its associated fauna, we unravelled the relationship between local (structural) and regional effects. We made specific predictions based on the structure of mussel beds from either the eastern or western region of the warm-temperate (Agulhas) biogeographic province of South Africa. We created patches of mussels based on the structure of mussel beds from both of these regions on each of the 2 shores within each region. We sampled the fauna associated with these biogenic habitats after $3 \mathrm{mo}$, and at the same time sampled undisturbed beds of mussels as a control to determine if artificially created mussel beds were similar to natural mussel beds. There were some experimental artefacts and the assemblages associated with the east structure were generally not the same as those from naturally occurring eastern mussel beds. Overall, our hypothesis was not supported; we found no evidence of the influence of the structure of mussel beds on assemblages of associated fauna. We found that within the same biogeographic province, assemblages only tens of $\mathrm{km}$ apart had very different groups of species. Contrary to previous studies, there was a de-coupling between the habitatforming taxon and its associated fauna. The existence of increased productivity through upwelling may reduce the importance of facilitation in both our study regions, so that larger-scale (shore or regional) effects had a stronger influence on associated fauna than habitat structure. Nevertheless, we suggest that, regardless of upwelling, shore and regional level effects can override those of habitat structure.
\end{abstract}

KEY WORDS: Ecosystem engineer $\cdot$ Intertidal $\cdot$ Perna perna $\cdot$ Rocky shore $\cdot$ Scale $\cdot$ Upwelling

Resale or republication not permitted without written consent of the publisher

\section{INTRODUCTION}

Understanding the scales at which organisms interact with each other and with their environment is essential for identifying the underlying processes that influence the abundance and distribution of species. Over the last few decades, there has been a strong research focus on the processes that influence intertidal assemblages at different spatial scales, with particular attention being paid to regional scales of tens to hundreds of km (Levin 1992, Underwood \&
Chapman 1996). Distinct patterns of distribution and abundance of intertidal organisms over meso-spatial scales, across tens to hundreds of $\mathrm{km}$, has been shown to be correlated with environmental gradients (McQuaid et al. 2000, Benedetti-Cecchi 2001), including temperature (Crisp 1964) and the supply of nutrients (Menge et al. 2004).

These well-recognised mechanisms are often modified within biogenic habitats via changes in habitat structure provided by the bioengineer (Kelaher \& Castilla 2005); they may be more complex due to 
indirect effects (Wieters 2005). Biogenic habitats have been recognised for their role in facilitation of positive effects on recruitment, species abundances and distributions, succession, and amelioration of physical stress and consumer pressure (Bertness \& Callaway 1994). Therefore, because foundation species alter the environment experienced by their associated assemblages, the structure of the habitat that they provide is important and the influence of bioengineering is often interwoven with environmental conditions (Crain \& Bertness 2006). Consequently, for assemblages associated with bioengineers, regional scale effects may differ between species living on the open shore and those living in biogenic habitats. The 'individual or population traits' of the bioengineers themselves may, therefore, be important in shaping these assemblages (Wieters 2005).

Mussels are common bioengineers on intertidal rocky shores around the world (Gutiérrez et al. 2003). They provide refuge from thermal stress (Stephens \& Bertness 1991), trap fine-grained sediments and organic particles (Tsuchiya \& Nishihira 1985, Crooks \& Khim 1999), provide surfaces for algae and epifauna (Seed \& Suchanek 1992, Lohse 1993), form a matrix for infauna (Lawrie \& McQuaid 2001, O'Connor \& Crowe 2007), and provide protection from predators (Lintas \& Seed 1994, Seed 1996, González \& Downing 1999). As a result, mussel beds form a habitat that supports diverse and abundant assemblages of species (Gutiérrez et al. 2003). Their role as providers of habitat is affected by properties of the mussel bed (or 'traits of a facilitator', Wieters 2005), such as differences in the size, age (Tsuchiya \& Nishihira 1986) and density of mussels (Stewart et al. 1998, Cole \& McQuaid 2010), as well as whether mussel beds are single or multi-layered (Palomo et al. 2007). For example, Tsuchiya \& Nishihira (1986) found different assemblages of organisms among mussels of different ages, with more sessile organisms being associated with older mussels. They suggested that recruitment of associated fauna is greater in younger mussel beds (due to lower filtration by the mussels) though this is balanced by less time for colonisation (Tsuchiya \& Nishihira 1986). O'Connor \& Crowe (2007) separated the effects of size and age of mussels and found differences in assemblages between small $(<2 \mathrm{~cm})$ and large $(>2 \mathrm{~cm})$ mussels, implying that mussel size alone may contribute to differences between beds of old and young mussels.

Mussel beds in 5 different regions (across 3 biogeographic provinces) along $3000 \mathrm{~km}$ of the coast of South Africa show strong effects of upwelling on both size and density of mussels but not on the asso- ciated fauna, which responded only to regional scale processes and not upwelling (Cole \& McQuaid 2010). There was also a strong relationship between biogeographic regional differences in densities of fauna inhabiting mussel beds and mussel bed structure (Cole \& McQuaid 2010). This implies a hierarchy of effects, including a primary effect of biogeography (establishing a regional pool of species, Levin 1992), while the mesoscale effects of upwelling are hidden by those of habitat structure. This provided us with a model system for testing the role of local (structural) and regional effects. Although mensurative experiments are important in providing observations (Underwood et al. 2000), unravelling the confounded influences producing the observed pattern requires experimental manipulations (Underwood 2000). Therefore, based on our previous observations (Cole \& McQuaid 2010), we used manipulative experiments to test specific predictions about the fauna associated with mussel beds, based on both mussel bed structure and regional scale processes.

To separate the effects of habitat structure from other factors operating independently at the regional scale, we compared 2 different regions, separated by $365 \mathrm{~km}$, within the warm-temperate South Coast (Agulhas) biogeographic province of South Africa. Each region included 2 different shores around a centre of upwelling. These were a relatively persistent upwelling cell to the east at Port Alfred and a western region experiencing summer seasonal upwelling driven by easterly summer winds off a headland at Robberg (Fig. 1, Lutjeharms 2006). The structure of mussel beds in the east consists of a

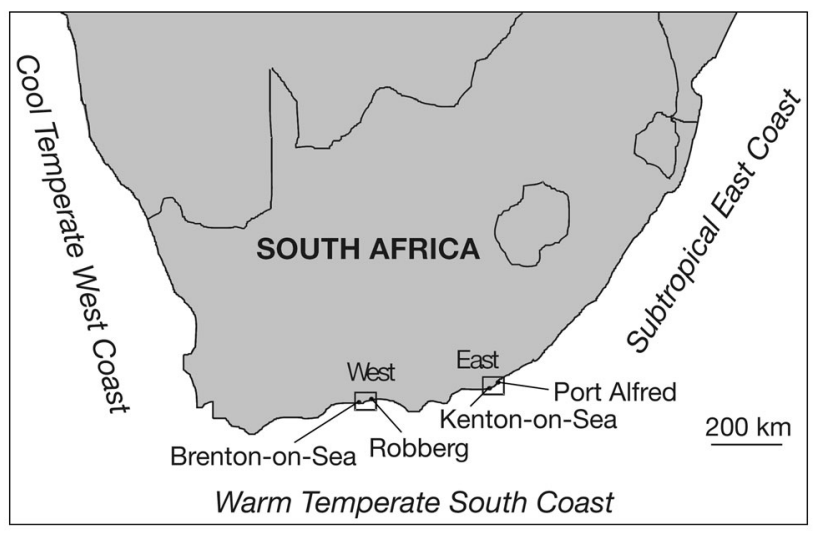

Fig. 1. Sampling locations in South Africa: warm-temperate South Coast biogeographic province in the western region (focused on the Knysna upwelling cell), with shores at Brenton-on-Sea and Robberg, and the eastern region (focussed on the Port Alfred upwelling), with shores at Kenton-on-Sea and Port Alfred 


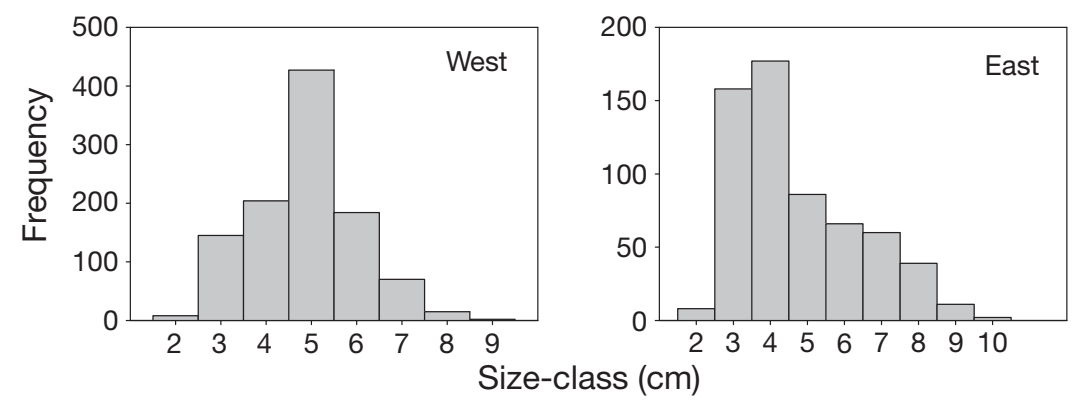

Fig. 2. Perna perna. Size frequency distributions of individuals from the eastern and western regions. Mussels were placed in $1 \mathrm{~cm}$ size classes, with the smallest and largest mussels being 2 and $11 \mathrm{~cm}$, respectively
To investigate the effect of the structure of mussel beds, independent of regional differences, the structure of mussel beds from eastern and western regions were created in both regions. The structure of mussel beds was determined by counting and measuring all mussels within 10 haphazardly selected $20 \times 20 \mathrm{~cm}$ quadrats in each 2 shores of both regions (Cole \& McQuaid 2010). Size-frequency histograms were constructed for mussels from each region by combining the data from the 20

greater proportion of smaller mussels whereas the west structure has more and larger mussels (Fig. 2). Smaller mussels may create more complex interstitial spaces, whereas larger mussels may provide greater surface area for attachment of epifauna. We predicted that if mussel bed structure has an overriding effect, there would be more epifauna on mussels associated with the west structure and more infauna associated with the east structure. Alternatively, if assemblages respond to the direct influence of regional processes, they should not differ between the 2 different structures, but there would be differences between the 2 regions regardless of mussel bed structure. We predicted that assemblages would differ in terms of both the abundances and the composition of taxa. Furthermore, we predicted that more persistent upwelling in the eastern region (Port Alfred) would lead to enhanced productivity, and thus decreased facilitation (e.g. Bruno et al. 2003), resulting in fewer species and densities than in the west (Robberg). We tested these hypotheses by experimentally manipulating mussel bed structure in the 2 regions.

\section{MATERIALS AND METHODS}

The warm-temperate South Coast biogeographic province of South Africa has multiple upwelling regions. There are 2 persistent upwelling centres focussed on Knysna and Port Alfred. Within each of these upwelling regions separated by $\sim 400 \mathrm{~km}$, the experiment was replicated at 2 shores separated by tens of km (Fig. 1). In the western region (focused on the Knysna upwelling cell), the experiment was replicated at Brenton-on-Sea and Robberg $(35 \mathrm{~km}$ apart). In the eastern region (focussed on the Port Alfred upwelling), the shores were at Kenton-on-Sea and Port Alfred (25 km apart). quadrats of both shores, and size-frequency distributions were compared with chi-squared contingency tests $\left(\chi^{2}=198\right.$, df $\left.=7, p<0.001\right)$. Based on theses regional size-frequencies (east and west) (Fig. 2), 2 separate treatments for mussel bed structure were constructed: (1) the East Structure and the (2) West Structure. Each structure was constructed by using the average density and size of mussels (from each of the 9 size classes) in each region, in $20 \times 20 \mathrm{~cm}$ quadrats using mussels collected from the shore from which they were deployed. A third treatment (Natural Structure) with undisturbed mussels was sampled as a control to determine if artificially created mussel beds represented natural mussel beds. Mussels for the East or West Structures were attached to the shore by placing them in large-gauged mesh bags (mesh hole size: $2.5 \mathrm{~cm}$, e.g. Cole 2010) and secured with bolts and shade cloth. Mussels were placed in cleared patches, not touching existing mussel beds, on the mid-low shore (within the 'low mussel zone', McQuaid et al. 2000). On each shore, 5 replicates of East, West, and Natural Structure treatments were deployed. After $3 \mathrm{mo}$, the mussels and associated fauna were collected. Samples were preserved in ethanol and then washed through a $0.5 \mathrm{~mm}$ sieve. All invertebrate fauna $>0.5 \mathrm{~mm}$ were retained and identified to the lowest taxonomic level possible. We had separate hypotheses about infaunal and epibiotic species so they were grouped accordingly. Epibiota were the fauna that grow on mussel shells and the mobile fauna that attach to the mussel shells. Infauna were the species that moved throughout the mussel matrix and were restricted to it (compared with Suchanek 1985, who differentiated 3 categories: epibiota, mobile fauna, and infauna).

To test our hypotheses, multivariate and univariate analyses were done. Multivariate analyses (PERMANOVA) and univariate analyses (ANOVA) used a 3 -factor design. The spatial factors were 'Region' and 
'Shore'; both were random with 2 levels. Shore was also nested in Region. The factor 'Structure' (3 levels: East Structure, West Structure and Natural Structure) was fixed and orthogonal. There were $\mathrm{n}=5$ replicates of each treatment on each shore in each region. Data for multivariate analyses were either untransformed to test hypotheses about the composition and abundance of assemblages, or presence/ absence transformed to test for differences in the composition of assemblages. To visualise differences in assemblages between regions and structures, nonmultidimensional scaling (nMDS) ordinations (Field et al. 1982) based on Bray-Curtis similarity matrices (Bray \& Curtis 1957) were plotted in PRIMER 6.1.11 (Clarke \& Gorley 2006). Data were analysed using permutational analysis of variance (PERMANOVA+, PRIMER 6 add on, Anderson et al. 2009), with 9999 permutations, based on Bray-Curtis dissimilarity measures that are suitable for biological assemblage data (Bray \& Curtis 1957). Pairwise post hoc comparisons were done to identify significant sources of variation to determine patterns of difference relative to the hypotheses of interest. To test for differences in numbers of taxa and densities of individuals between regions, shores nested in regions, and among structures, data were analysed with ANOVAs. Prior to analyses, data were tested for homogeneity of variances with Cochran's C-test. Variances were generally homogeneous and therefore did not require transformation. For those that did, few required the same transformation to create homogeneous variances. Therefore, in order to make simple comparisons among taxa, none of the data were transformed. The violation of homogeneity of variances was considered to be acceptable because ANOVA is relatively robust to heterogeneous variances for large designs such as this (Underwood 1997). When sources of variation for univariate analyses were shown to be significant, Student-Newman-Keuls (SNK) tests were used to compare means.

\section{RESULTS}

A total of 93 invertebrate species associated with mussel beds were identified, with 83 species in the eastern region and 79 in the western region, of which 64 and $66 \%$, respectively, were common to both regions. The infaunal taxa included errant polychaetes, crabs, amphipods, isopods and some gastropods. Abundant among these were the polychaetes Pseudonereis variegata, Naineris laevigata, and Syllis prolifera; and the crustaceans Corophium acheru-
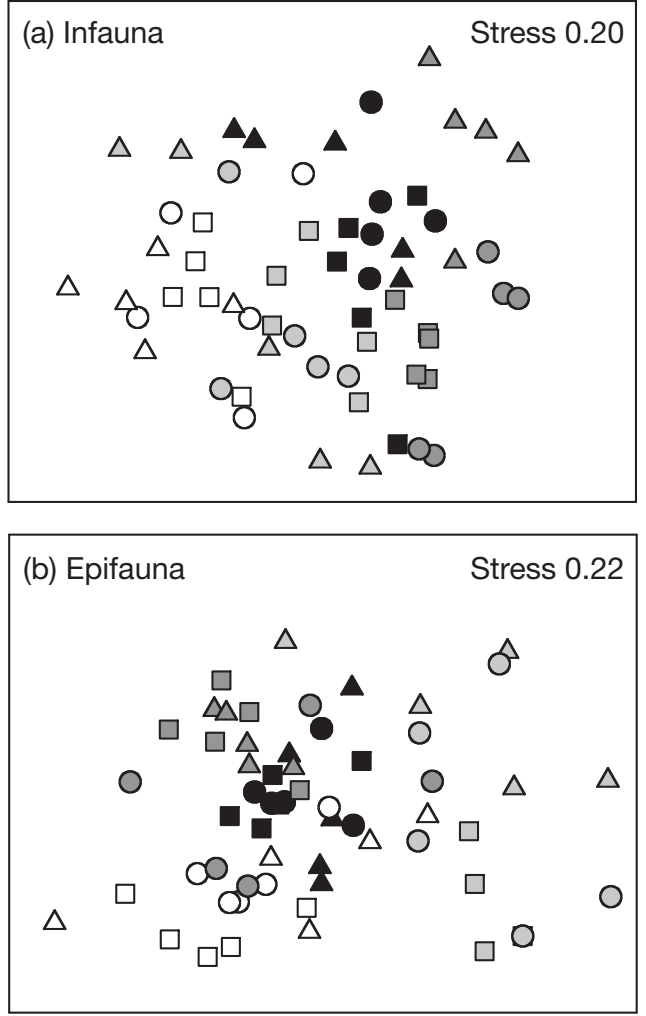

Fig. 3. Non-multidimensional scaling (nMDS) plots of assemblages of (a) infauna and (b) epifauna associated with mussels from 2 shores in the east and 2 in the west region. East region: Port Alfred (black) and Kenton (dark grey). West region: Robberg (light grey) and Brenton (white). In each site, 3 structures: Natural $(\Delta)$, East $(\square)$, and West $(O)$ Structures; $(n=5)$

sicum (Amphipoda), Tanais philetaerus (Tanaidacea) and Dymanella huttoni (Isopoda). Epifaunal taxa included tubeworms, barnacles, limpets and chitons. Abundant among the epifauna were sessile species, the tubeworm Gunnerea capensis, and the barnacles Tetraclita serrata, Octomeris angulosa and Chthamalus dentatus; and mobile species, particularly the limpet Scutellastra granualis, the seastar Pateriella exigua and the anemone Aulactina reynaudi.

nMDS ordinations showed no clear patterns according to the different habitat structures but there were some patterns that reflected regional differences (Fig. 3a,b). Stress values were relatively high $(\geq 0.2)$, and therefore the representations should be considered with caution, but generally, samples from the same regions tended to group together regardless of structure (Fig. 3a,b). There was, however, some overlap between regions and the pattern was stronger for the infauna (Fig. 3a) than for the epi- 
Table 1. PERMANOVA of untransformed data of assemblages of (a) infauna, and (b) epifauna, comparing Regions (Re) (east and west), with nested Shores (Sh) (east: Port Alfred [PA] and Kenton [Kent], west: Robberg [Rob] and Brenton [Bren]) and orthogonal to Structure (St) (Natural [Nat], West [W] and East [E]), n $=5$ replicates per shore. Pairwise post hoc comparisons were done for significant sources of variation to determine patterns of interest relative to the hypotheses of interest. ns: not significant, ${ }^{*} p<0.05,{ }^{* *} p<0.01,{ }^{* * *} p<0.001$

\begin{tabular}{|c|c|c|c|c|c|c|c|}
\hline \multirow[t]{2}{*}{ Source } & \multirow[t]{2}{*}{ df } & \multicolumn{3}{|c|}{ - (a) Infauna- } & \multicolumn{3}{|c|}{-(b) Epifauna- } \\
\hline & & MS & Pseudo- $F$ & $\mathrm{p}$ & MS & Pseudo- $F$ & $\mathrm{p}$ \\
\hline $\mathrm{Re}$ & 1 & 15280 & 1.95 & $* * *$ & 21005 & 2.71 & $* * *$ \\
\hline $\mathrm{Sh}(\mathrm{Re})$ & 2 & 10998 & 7.13 & $* * *$ & 10774 & 6.18 & $* * *$ \\
\hline St & 3 & 4507 & 2.06 & ns & 5154 & 3.95 & ns \\
\hline $\mathrm{Re} \times \mathrm{St}$ & 2 & 2191 & 0.97 & ns & 1304 & 0.40 & ns \\
\hline $\mathrm{Sh}(\mathrm{Re}) \times \mathrm{St}$ & 4 & 2248 & 1.46 & $*$ & 3236 & 1.86 & ${ }^{* *}$ \\
\hline Residual & 48 & 1542 & & & 1743 & & \\
\hline Total & 59 & & & & & & \\
\hline Pairwise & \multicolumn{4}{|c|}{$\begin{array}{l}\text { PA \& Kent: Nat } \neq \mathrm{W}=\mathrm{E} \\
\text { Bren \& Rob: Nat }=\mathrm{W}=\mathrm{E}\end{array}$} & \multicolumn{3}{|c|}{$\begin{array}{l}\text { A \& Kent: Nat } \neq \mathrm{W}=\mathrm{E} \\
\text { Bren \& Rob: Nat }=\mathrm{W}=\mathrm{E}\end{array}$} \\
\hline
\end{tabular}

Brenton or Robberg (Table 2b). The pattern at Kenton was as predicted, with the Natural Structure being similar to the East Structure and different from the West Structure (Table 2b).

When comparing the numbers of species and numbers of individuals, neither of our proposed models was supported (Tables $3 \& 4$ ). Contrary to our predictions, there were no significant differences among structures and there were no differences according to whether the fauna were infauna (Table 3) or epifauna (Table 4). Furthermore, there were no differences in the densities of infauna (Table 3) or epifauna (Table 4) between the eastern and western regions.

Similarly, when comparing densities of the 4 most abundant infaunal or epifaunal species that were present in both regions, there were again no significant

fauna (Fig. 3b). Moreover, PERMANOVA results for both the infauna and the epifauna showed that Structure interacted with Shore, and there was a significant effect of Region (Table 1a,b). Pair-wise tests investigating the interaction between Structure and Shore showed that for the 2 shores in the eastern region, Port Alfred and Kenton, the 2 manipulated structures (East and West Structures) differed significantly from the Natural Structure (Table 1a,b). At the 2 shores in the western region, Brenton and Robberg, there were no differences among the 3 structures (Table 1a,b). These patterns were also similar for infauna and epifauna (Table 1a,b).

In general, comparisons of transformed presence/absence data showed similar results to comparisons of untransformed data (Table 2a,b). Again, for both infauna and epifauna, there was a significant effect of Region and a significant interaction of Shore with Structure (Table 2a,b). Pair-wise tests of the interaction of Shore and Structure showed that at Port Alfred and Kenton, the composition of assemblages associated with the Natural Structure differed significantly from the East Structure (Table 2a). In Port Alfred, the East Structure was not different from the West Structure, but in Kenton there was a significant difference between the 2 structures (Table 2a). For epifauna, the structures did not differ in Port Alfred, differences between regions. For 2 of the infauna species, the nereid polychaete Pseudonereis variegata and the isopod Dymanella huttoni, there was no effect of Structure or Region, but there was a significant effect of Shore (Table 5a). For the tube-dwelling amphipod Corophium acherusicum, there were no significant differences between regions, shores or structures (Table 5a). For the tanaid Tanais philetaerus, there was a significant Shore by Structure interaction (Table 5a). At Kenton, all the structures significantly differed but there was no difference

Table 2. PERMANOVA of presence/absence data of assemblages of (a) infauna and (b) epifauna, comparing Regions (Re) (east and west), with nested Shores (Sh) (east: Port Alfred and Kenton, west: Robberg and Brenton) and orthogonal to Structure (St) (Natural, West and East), n = 5 replicates per shore. Pairwise post hoc comparisons were done for significant sources of variation to determine patterns of interest relative to the hypotheses of interest. ns: not significant, ${ }^{*} \mathrm{p}<0.05,{ }^{* *} \mathrm{p}<0.01$, ${ }^{* * *} \mathrm{p}<0.001$. See Table 1 for definitions

\begin{tabular}{|c|c|c|c|c|c|c|c|}
\hline \multirow[t]{2}{*}{ Source } & \multirow[t]{2}{*}{$\mathrm{df}$} & \multicolumn{3}{|c|}{ (a) Infauna- } & \multicolumn{3}{|c|}{ (b) Epifauna } \\
\hline & & MS & Pseudo- $F$ & $\mathrm{p}$ & MS & Pseudo- $F$ & $\mathrm{p}$ \\
\hline $\operatorname{Re}$ & 1 & 8586 & 2.27 & $* * *$ & 13752 & 2.11 & $* * *$ \\
\hline $\operatorname{Sh}(\operatorname{Re})$ & 2 & 5377 & 8.85 & $* * *$ & 9183 & 7.53 & $* * *$ \\
\hline St & 3 & 1754 & 2.20 & ns & 3074 & 3.44 & ns \\
\hline $\mathrm{Re} \times \mathrm{St}$ & 2 & 798 & 0.66 & ns & 894 & 0.35 & ns \\
\hline $\mathrm{Sh}(\mathrm{Re}) \times \mathrm{St}$ & 4 & 1218 & 2.01 & $* *$ & 2584 & 2.12 & $* *$ \\
\hline Residual & 48 & 607 & & & 1219 & & \\
\hline Total & 59 & & & & & & \\
\hline Pairwise & $\begin{array}{l}\mathrm{P} \\
\mathrm{K} \\
\mathrm{B}\end{array}$ & $\begin{array}{l}\text { Nat } \neq 1 \\
\text { Nat } \neq \\
\& \text { Rok }\end{array}$ & $\begin{array}{l}N=E \\
S \neq E \\
: N a t=W\end{array}$ & & $\begin{array}{l}\text { PA: Nat } \\
\text { Kent: Na } \\
\text { Bren \& R }\end{array}$ & $\begin{array}{l}=W=E \\
t=E \neq W \\
\text { Rob: } N a t=\end{array}$ & $=\mathrm{E}$ \\
\hline
\end{tabular}


Table 3. ANOVA of infauna comparing (a) numbers of species, and (b) numbers of individuals from 2 Regions ( $R e$ ) (east and west), with nested Shores (Sh) (east: Port Alfred and Kenton, west: Robberg and Brenton) and orthogonal to Structure (St) (Natural, West and East), $\mathrm{n}=5$ replicates per shore. Variances were homogeneous (Cochran's $C$-test). ns: not significant, ${ }^{*} \mathrm{p}<0.05,{ }^{* *} \mathrm{p}<0.01,{ }^{* * *} \mathrm{p}<0.001$

\begin{tabular}{|c|c|c|c|c|c|c|c|}
\hline \multirow[t]{2}{*}{ Source } & \multirow[t]{2}{*}{$\mathrm{df}$} & \multicolumn{3}{|c|}{$\begin{array}{c}\text { (a) No. of species } \\
C=0.27 \text { (ns) }\end{array}$} & \multicolumn{3}{|c|}{$\begin{array}{c}\text { (b) No. of individuals } \\
C=0.23 \text { (ns) }\end{array}$} \\
\hline & & MS & $F$ & $\mathrm{p}$ & MS & $F$ & $\mathrm{p}$ \\
\hline $\operatorname{Re}$ & 1 & 0.15 & 0.00 & 0.9788 & 24543 & 10.27 & 0.0851 \\
\hline $\mathrm{Sh}(\mathrm{Re})$ & 2 & 166.68 & 7.74 & $* *$ & 2390 & 0.48 & 0.6224 \\
\hline St & 2 & 61.32 & 6.10 & 0.1408 & 1764 & 0.13 & 0.8865 \\
\hline $\mathrm{Re} \times \mathrm{St}$ & 2 & 10.05 & 0.65 & 0.5700 & 13775 & 2.76 & 0.0728 \\
\hline $\mathrm{Sh}(\mathrm{Re}) \times \mathrm{St}$ & 4 & 15.48 & 0.72 & 0.5833 & $3934^{\mathrm{a}}$ & & \\
\hline Residual & 48 & 21.54 & & & $5084^{\mathrm{a}}$ & & \\
\hline Total & 59 & & & & & & \\
\hline Pooled & 52 & & & & 4996 & & \\
\hline
\end{tabular}

Table 4. ANOVA of epifauna comparing (a) numbers of species, and (b) numbers of individuals from 2 Regions (Re) (east and west), with nested Shores (Sh) (east: Port Alfred and Kenton, west: Robberg and Brenton), and orthogonal to Structure (St) (Natural, West and East); $\mathrm{n}=5$ replicates per shore. Variances were homogeneous (Cochran's $C$-test). ns: not significant, ${ }^{*} p<0.05,{ }^{* *} p<0.01,{ }^{* * *} p<0.001$

\begin{tabular}{|c|c|c|c|c|c|c|c|}
\hline \multirow[t]{2}{*}{ Source } & \multirow[t]{2}{*}{$\mathrm{df}$} & \multicolumn{3}{|c|}{$\begin{array}{c}\text { (a) Number of species } \\
C=0.23(\mathrm{~ns})\end{array}$} & \multicolumn{3}{|c|}{$\begin{array}{c}\text { (b) No. of individuals } \\
C=0.26(\mathrm{~ns})\end{array}$} \\
\hline & & MS & $F$ & $\mathrm{p}$ & MS & $F$ & $\mathrm{p}$ \\
\hline $\operatorname{Re}$ & 1 & 70.4 & 0.75 & ns & 322 & 0.38 & ns \\
\hline St & 2 & 6.5 & 0.55 & ns & 273 & 1.34 & ns \\
\hline $\mathrm{Sh}(\mathrm{Re})$ & 2 & 93.8 & 14.87 & $* * *$ & 839 & 7.60 & $* *$ \\
\hline $\mathrm{Re} \times \mathrm{St}$ & 2 & 11.7 & 6.11 & ns & 204 & 1.31 & ns \\
\hline $\mathrm{Sh}(\mathrm{Re}) \times \mathrm{St}$ & 4 & 1.9 & 0.30 & ns & 155 & 1.41 & ns \\
\hline Residual & 48 & 6.3 & & & 110 & & \\
\hline Total & 59 & & & & & & \\
\hline
\end{tabular}

\section{DISCUSSION}

It is essential to 'control' for potentially confounding artefacts in any experimental manipulation (see Underwood 2009 for review). Although care was taken to ensure the correct procedural controls were included in the experiment, there were some experimental artefacts and therefore some results should be treated with caution. Specifically, in most cases there was an interaction of Structure with Shore; assemblages associated with the East Structure generally differed from those in naturally occurring mussel beds. Differences between the Natural Structure and the structures that were created from the eastern or western regions may be due to artificially created mussel beds representing an earlier successional state (sensu Connell \& Slayter 1977, Greene \& Schoener 1982). This experiment was left in the field for $3 \mathrm{mo}$ but it may take longer than 3 mo for colonisation of completely defaunated mussel beds to match assemblages occurring in undisturbed mussel beds. Although the composition of assemblages differed between natural and artificially constructed mussel beds, there were similar numbers of species and overall densities of individuals. This supports the suggestion that post-recruitment processes (e.g. competition, Connell 1985), leading to different successional states may help to explain among structures at any of the other sites (Table 5a). Similarly for 2 of the species of epifauna, the anemone Aulactina reynaudi and the seastar Pateriella exigua, there was no effect of Structure or Region, but there was a significant effect of Shore (Table 5b). There were significant effects of Shore and Structure for the limpet Scutellastra granularis (Table 5b). Specifically, the Natural Structure differed from the East and the West Structure (SNK p < 0.05). For another barnacle, Tetraclita serrata, there was a significant interaction between Shore and Structure (Table 5b). Specifically, in Port Alfred the Natural Structure was similar to the East Structure and different from the West Structure (Table 5b). On all other shores, there were no differences among structures (SNK p > 0.05).
Table 5. ANOVAs of 4 most abundant species of (a) infauna and (b) epifauna showing significant sources of variation. ns: not significant, ${ }^{*} \mathrm{p}<0.05,{ }^{* *} \mathrm{p}<0.01,{ }^{* * *} \mathrm{p}<0.001$
(a) Infauna
Pseudonereis variegata
Dymanella huttoni
Corophium acherusicum
Tanais philetaerus
(b) Epifauna
Aulactina reynaudi
Pateriella exigua
Scutellastra granularis
Tetraclita serrata

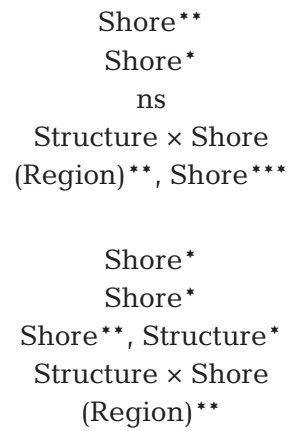

Shore ${ }^{* *}$

Shore*

ns

Structure $\times$ Shore

(Region) ${ }^{* *}$, Shore ${ }^{* * *}$

Shore*

Shore*

Shore $^{* *}$, Structure ${ }^{*}$

Structure $\times$ Shore

(Region) ** 
the observed experimental artefact. Thus, we can only make inferences about assemblages 3 mo old and must recognise that important post-recruitment processes may be critical.

We expected that the different habitat structures in the eastern and western regions would offer different physical and biological environments in terms of amelioration of heat and desiccation stress (Stephens \& Bertness 1991), but also in terms of the size (Tsuchiya 2002) and configuration of the spaces among mussels (Suchanek 1985), protection from predators (Lively \& Raimondi 1987), deposition of sediment (Tsuchiya 2002), and the byssal thread matrix (Tsuchiya \& Nishihira 1985). Contrary to our hypotheses, we found no evidence of any influences of the habitat structure of mussels on assemblages of associated fauna. We suggest that any direct effects of habitat structure on the associated fauna may be masked by stronger regional or local-scale effects. This can be interpreted as support for the theoretical model proposed by Bruno et al. (2003): the occurrence of upwelling results in higher productivity that reduces the importance of facilitation, minimising the importance of the structural 'traits' of the bioengineer.

Our regional comparisons were done in the same biogeographic province in order to draw from the same pool of taxa (Underwood \& Petraitis 1993). Nevertheless, our analyses showed that, even within the same biogeographic province, assemblages only tens of $\mathrm{km}$ apart consisted of very different groups of species. Significant effects of region for infauna and epifauna for both untransformed data and presence/absence data indicate that regional differences resulted in a very different type of assemblage in the eastern region from the western region (Clarke 1993). Processes that may contribute to differences between regions in the same biogeographic province could be linked to factors influencing the recruitment of certain species such as the timing and delivery of larvae. Coastal topography has a strong influence on the retention and dispersal of larvae, with bays, coastal embayments and upwelling-shadows retaining larvae (Largier 2004). Although the coastal topography differs between the eastern and western regions, this study was done on the open coast and in upwelling areas, which are all non-retentive environments. Within the warm-temperate South Coast biogeographic province, there is weak synchrony in the spawning or recruitment of conspecific intertidal organisms (McQuaid \& Lawrie 2005). This could be due to differences in the intensity and timing of upwelling (Morgan \& Fisher 2010) or temperature (Tapia \& Navarrete 2010). For example, Lagos et al. (2008) found that the mesoscale environmental variables, intensity of upwelling and wind-velocity were negatively related to recruitment of barnacles.

The numbers and densities of different species therefore contributed little to the regional differences that were observed at the assemblage level. Moreover, analyses of the number of species of epifauna and infauna and the number of individuals of epifauna showed significant differences between shores. Densities of many of the abundant species (Dymanella huttoni, Pseudonereis variegata, Aulactina reynaudi and Pateriella exigua) also differed between shores. These shore to shore differences were not predicted and could be due to a range of physical and biological factors that produce idiosyncratic differences at the $\mathrm{km}$ scale (e.g. Underwood \& Chapman 1996). These results suggest that among the common species, rather than the rarer taxa, generally varied within regions and did not contribute to our previously observed differences in assemblages associated with mussel beds at the regional scale.

Overall, our main finding was that there was a decoupling between the habitat-forming taxon and its associated fauna, at least at a relatively early successional stage. Earlier work detected regional differences in mussel bed structure and the associated fauna (Cole \& McQuaid 2010), leaving 2 possible explanations. Here we used a manipulative experiment to show that direct effects of region over-ride the indirect processes operating through habitat structure. Thus, effects of region directly influenced faunal assemblages, independent of mussel bed structure. Our findings are contrary to previous studies that have found a link between the structure of bioengineers and associated fauna (Kelaher \& Castilla 2005, Wieters 2005), and can be interpreted in 2 ways. (1) The presence of upwelling results in increased productivity and consequently decreased importance of facilitation in both our study regions, so that larger-scale (shore or regional) effects had a stronger influence on the composition of the associated fauna than habitat structure. (2) Because we worked only within upwelling regions, we cannot discard the possibility that shore and regional level effects are so powerful that they override those of habitat structure regardless of the presence of upwelling. Critically, only the use of experimental manipulations allowed us to unravel influences on the associated fauna that operate at different spatial scales (e.g. Underwood 2000). 
Acknowledgements. This work is based upon research supported by the South African Research Chairs Initiative of the Department of Science and Technology and National Research Foundation (CDM) and a Rhodes University Postdoctoral Fellowship (VJC). Assistance was provided in the field by A. Becker, L.G. Johnson, E.R. Pesce, B.P. Mostert, C.E.O. von der Meden, and A. Ludford, and in the laboratory by A. Twani. We are grateful to 3 anonymous reviewers whose suggestions greatly improved an earlier draft of this manuscript.

\section{LITERATURE CITED}

Anderson MJ, Gorley RN, Clarke KR (2009) PERMANOVA+ for PRIMER: guide to Software and Statistical Methods. PRIMER-E, Plymouth

> Benedetti-Cecchi L (2001) Variability in abundance of algae and invertebrates at different spatial scales on rocky sea shores. Mar Ecol Prog Ser 215:79-92

> Bertness MD, Callaway R (1994) Positive interactions in communities. Trends Ecol Evol 9:191-193

$>$ Bray JR, Curtis JT (1957) An ordination of the upland forest communities of Southern Wisconsin. Ecol Monogr 27: 325-349

$>$ Bruno JF, Stachowicz JJ, Bertness MD (2003) Inclusion of facilitation into ecological theory. Trends Ecol Evol 18: $119-125$

Clarke KR (1993) Non-parametric multivariate analyses of changes in community structure. Aust J Ecol 18:117-143

Clarke KR, Gorley RN (2006) PRIMER v6: user manual/tutorial. PRIMER-E, Plymouth

> Cole VJ (2010) Alteration of the configuration of bioengineers affects associated taxa. Mar Ecol Prog Ser 416: $127-136$

> Cole VJ, McQuaid CD (2010) Bioengineers and their associated fauna respond differently to the effects of biogeography and upwelling. Ecology 91:3549-3562

Connell JH (1985) The consequences of variation in initial settlement vs. post-settlement mortality in rocky intertidal communities. J Exp Mar Biol Ecol 93:11-45

Connell JH, Slayter O (1977) Mechanisms of succession in natural communities and their role in community stability and organisation. Am Nat 111:1119-1144

> Crain CM, Bertness MD (2006) Ecosystem engineering across environmental gradients: implications for conservation and management. Bioscience 56:211-218

Crisp DJ (1964) The effects of the severe winter of 1962-63 on marine life in Britain. J Anim Ecol 33:165-210

> Crooks JA, Khim HS (1999) Architectural vs. biological effects of a habitat-altering, exotic mussel, Musculista senhousia. J Exp Mar Biol Ecol 240:53-75

Field JG, Clarke KR, Warwick RM (1982) A practical strategy for analysing multispecies distribution patterns. Mar Ecol Prog Ser 8:37-52

> González MJ, Downing A (1999) Mechanisms underlying amphipod responses to zebra mussel (Dreissena polymorpha) invasion and implications for fish-amphipod interactions. Can J Fish Aquat Sci 56:679-685

> Greene CH, Schoener A (1982) Succession on marine hard substrata: a fixed lottery. Oecologia 55:289-297

Gutiérrez JL, Jones CG, Strayer DL, Iribarne OO (2003) Mollusks as ecosystem engineers: the role of shell production in aquatic habitats. Oikos 101:79-90

Kelaher BP, Castilla JC (2005) Habitat characteristics influ- ence macrofauna communities in coralline turf more than mesoscale coastal upwelling on the coast of Northern Chile. Estuar Coast Shelf Sci 63:155-165

- Lagos NA, Castilla AC, Broitman BR (2008) Spatial environmental correlates of intertidal recruitment: a test of using barnacles in Northern Chile. Ecol Monogr 78:245-261

Largier JL (2004) The importance of retention zones in the dispersal of larvae. Am Fish Soc Symp 42:105-122

- Lawrie SM, McQuaid CD (2001) Scales of mussel bed complexity: structure, associated biota and recruitment. J Exp Mar Biol Ecol 257:135-161

> Levin SA (1992) The problem of pattern and scale in ecology. Ecology 73:1943-1967

> Lintas C, Seed R (1994) Spatial variation in the fauna associated with Mytilus edulis on a wave-exposed rocky shore. J Molluscan Stud 60:165-174

> Lively CM, Raimondi PT (1987) Desiccation, predation, and mussel-barnacle interactions in the northern Gulf of California. Oecologia 74:304-309

> Lohse DP (1993) The importance of secondary substratum in a rocky intertidal community. J Exp Mar Biol Ecol 166: $1-17$

Lutjeharms JRE (2006) The Agulhas Current. Springer, Heidelberg

$>$ McQuaid CD, Lawrie SM (2005) Supply-side ecology of the brown mussel, Perna perna: an investigation of spatial and temporal variation in, and coupling between, gamete release and larval supply. Mar Biol 147:955-963

McQuaid CD, Lindsay JR, Lindsay TL (2000) Interactive effects of wave exposure and tidal height on population structure of the mussel Perna perna. Mar Biol 137: 925-932

> Menge BA, Blanchette C, Raimondi P, Freidenburg T and others (2004) Species interaction strength: testing model predictions along an upwelling gradient. Ecol Monogr 74:663-684

Morgan SG, Fisher JL (2010) Larval behavior regulates nearshore retention and offshore migration in an upwelling shadow and along the open coast. Mar Ecol Prog Ser 404:109-126

> O'Connor NE, Crowe TP (2007) Biodiversity among mussels: separating the influence of sizes of mussels from the ages of patches. J Mar Biol Assoc U K 87:551-557

Palomo MG, People J, Champan MG, Underwood AJ (2007) Separating the effects of physical and biological aspects of mussel beds on their associated assemblages. Mar Ecol Prog Ser 344:131-142

> Seed R (1996) Patterns of biodiversity in the macro-invertebrate fauna associated with mussel patches on rocky shores. J Mar Biol Assoc U K 76:203-210

Seed R, Suchanek TH (1992) Population and community ecology of Mytilus. In: Gosling EM (ed) The mussel Mytilus: ecology, physiology, genetics and culture. Elsevier Press, Amsterdam, p 87-169

> Stephens EG, Bertness MD (1991) Mussel facilitation of barnacle survival in a sheltered bay habitat. J Exp Mar Biol Ecol 145:33-48

Stewart TW, Miner JG, Lowe RL (1998) Quantifying mechanisms for zebra mussel effects on benthic macroinvertebrates: organic matter production and shell-generated habitat. J N Am Benthol Soc 17:81-94

Suchanek TH (1985) Mussels and their role in structuring rocky shore communities. In: Moore PG, Seed R (eds) The ecology of rocky coasts. Hodder and Stoughton, London, p 70-96 
Tapia FJ, Navarrete SA (2010) Spatial patterns of barnacle settlement in central Chile: persistence at daily to interannual scales relative to the spatial signature of physical variability. J Exp Mar Biol Ecol 392:151-159

Tsuchiya M (2002) Faunal structures associated with patches of mussels on East Asian coasts. Helgol Mar Res 56:31-36

Tsuchiya M, Nishihira M (1985) Islands of Mytilus as a habitat for small intertidal animals: effect of island size on community structure. Mar Ecol Prog Ser 25:71-81

Tsuchiya M, Nishihira M (1986) Islands of Mytilus edulis as a habitat for small intertidal animals: effect of Mytilus age structure on the species composition of the associated fauna and community organisation. Mar Ecol Prog Ser 31:171-178

Underwood AJ (1997) Ecological experiments: their logical design and interpretation using analysis of variance. Cambridge University Press, Melbourne

Underwood AJ (2000) Experimental ecology of rocky intertidal habitats: What are we learning? J Exp Mar Biol Ecol

Editorial responsibility: Antony Underwood, Sydney, Australia
250:51-76

Underwood AJ (2009) Components of design in ecological field experiments. Ann Zool Fenn 46:93-111

> Underwood AJ, Chapman MG (1996) Scales of spatial patterns of distribution of intertidal invertebrates. Oecologia 107:212-224

Underwood AJ, Petraitis PS (1993) Structure of intertidal assemblages in different locations: How can local processes be compared? In: Ricklefs R, Schlute D (eds) Species diversity in ecological communities: historical and geographical perspectives. University of Chicago Press, Chicago, IL, p 38-51

- Underwood AJ, Chapman MG, Connell SD (2000) Observations in ecology: you can't make progress on processes without understanding the patterns. J Exp Mar Biol Ecol 250:97-115

> Wieters E (2005) Upwelling control of positive interactions over mesoscales: a new link between bottom-up and topdown processes on rocky shores. Mar Ecol Prog Ser 301: $43-54$

Submitted: December 20, 2010; Accepted: September 16, 2011 Proofs received from author(s): November 21, 2011 